\title{
Seroprevalence of Bovine Foot and Mouth Disease (FMD) and Its Associated Risk Factors in Selected Districts of Afar Region, Ethiopia
}

\author{
Teshager Tegegne ${ }^{1}$, Tesfaw Mitiku ${ }^{1}$, and Wossene Mengesha ${ }^{1}$ \\ ${ }^{1}$ Affiliation not available
}

May 12, 2020

\begin{abstract}
Foot and mouth disease is an extremely contagious transboundary disease of livestock that causes significant economic losses in Ethiopia. A cross sectional study was conducted from November 2018 to May 2019 to estimate seroprevalence and to assess associated risk factors in selected districts of afar region. Purposive and simple random sampling technique was employed to select the study areas and animals respectively. A total of 384 sera were collected from 72 herds and seroprevalence of the disease was determined using 3ABC-ELISA technique. Data generated from laboratory reports and questionnaire survey was recorded and coded using Microsoft Excel spreadsheet and analyzed using STATA version 14. Potential risk factors of the disease were also assessed using logistic regression analysis. Out of 384 sera tested, the overall seroprevalence of FMDV was $19.8 \%(\mathrm{n}=76 ; 95 \% \mathrm{CI}=15.8-23.79)$ at animal level and 56.94\% at herd level. The herd level seroprevalence was higher in animals tested from Dubti $(85 \%, \mathrm{n}=17)$ than those from Asayita $(48.13 \%, \mathrm{n}=13)$ and Chifra $(44 \%, \mathrm{n}=11)$. Among the associated risk factors, age, herd size, district and contact with wild life were statistically associated with FMDV serostatus $(\mathrm{P}<0.05)$. Medium and large herd size animals were 2.49 (95\% CI: 1.33-6.63) and 6.05(95\% CI: 2.54-14.43) times more likely to develop the disease as compared to those animals from small herd size respectively. Adult cattle were 2.97 times more likely to have a chance of contracting the disease as compared to young cattle. The current study finding revealed that FMD was more prevalent and economically significant disease in the study districts. Hence, further studies ought to be conducted to estimate the region wise magnitude of the disease and to identify and characterize the circulating serotypes and strains in the areas.
\end{abstract}

\section{Seroprevalence of Bovine Foot and Mouth Disease (FMD) and Its Associated Risk Factors in Selected Districts of Afar Region, Ethiopia}

Teshager Dubie ${ }^{1,2^{*}}$, Tesfaw Molla ${ }^{2}$ and Wossene Negash ${ }^{2}$

${ }^{1}$ Research and community service, Samara University, P.O. Box 132, Samara, Ethiopia

${ }^{2}$ College of Veterinary Medicine, Samara University, P.O. Box 132, Samara, Ethiopia.

*Correspondence author's address: E-mail; teshagerdubie@su.edu.et/teshager.dubie@yahoo.com

\section{Summary}

Foot and mouth disease is an extremely contagious transboundary disease of livestock that causes significant economic losses in Ethiopia. A cross sectional study was conducted from November 2018 to May 2019 to estimate seroprevalence and to assess associated risk factors in selected districts of afar region. Purposive and simple random sampling technique was employed to select the study areas and animals respectively. A total of 384 sera were collected from 72 herds and seroprevalence of the disease was determined using $3 \mathrm{ABC}-$ ELISA technique. Data generated from laboratory reports and questionnaire survey was recorded and coded using Microsoft Excel spreadsheet and analyzed using STATA version 14. Potential risk factors of the disease 
were also assessed using logistic regression analysis. Out of 384 sera tested, the overall seroprevalence of FMDV was $19.8 \%(\mathrm{n}=76 ; 95 \% \mathrm{CI}=15.8-23.79)$ at animal level and $56.94 \%$ at herd level. The herd level seroprevalence was higher in animals tested from Dubti $(85 \%, \mathrm{n}=17)$ than those from Asayita $(48.13 \%$, $\mathrm{n}=13)$ and Chifra $(44 \%, \mathrm{n}=11)$. Among the associated risk factors, age, herd size, district and contact with wild life were statistically associated with FMDV serostatus $(\mathrm{P}<0.05)$. Medium and large herd size animals were 2.49 (95\% CI: 1.33-6.63) and 6.05(95\% CI: 2.54-14.43) times more likely to develop the disease as compared to those animals from small herd size respectively. Adult cattle were 2.97 times more likely to have a chance of contracting the disease as compared to young cattle. The current study finding revealed that FMD was more prevalent and economically significant disease in the study districts. Hence, further studies ought to be conducted to estimate the region wise magnitude of the disease and to identify and characterize the circulating serotypes and strains in the areas.

Key words : Afar, Bovine, 3ABC-ELISA, FMD, Risk factor, Seroprevalence

\section{Background}

Ethiopia has the most abundant livestock population among African countries with an estimated domestic animal number of 56.71 million cattle, 29.33 million sheep, 29.11 million goats and 54.5 million chickens are found in Ethiopia (CSA, 2016). The livestock sector plays a crucial role in the livelihoods of majority of human population in the country. The agricultural sector constitutes around $45-48 \%$ of the gross domestic production (GDP) of the country and livestock sector accounts an estimated $20 \%$ of the total GDP without considering other contribution like traction power, fertilizing and mean of transport (CSA, 2009; Gebreegziabhare, 2010). Even though the country is gifted with huge livestock population, production and productivity is by far underneath the expectation due to widespread of livestock diseases and other constraints (Livestock Master Plan, 2015).

Livestock diseases are the major cause of economic losses to the peasant farmers and pastoralists in Ethiopia amounting to hundreds of millions of birr annually. These diseases are currently widespread in all agroecological zones of the country and annual mortality rates due to these diseases is estimated to be $8-10 \%$ for cattle herds, $15 \%$ and $12 \%$ sheep and goat flocks respectively. It is expected that animal diseases reduce production and productivity of livestock by $50-60 \%$ per year (Ganeshkumar, 2012). Among the livestock diseases hampering productivity of the sector and restrict Ethiopia's ability to participate in international trade, foot-and-mouth disease (FMD) is perceived as the most economically important transboundary viral disease of cattle both at national and house hold levels (OIE, 2010; Bayissa et al ., 2011; Asseged, 2005).

Foot and mouth disease (FMD) is an extremely contagious and acute viral disease of all cloven-hoofed animals and is considered as a bottleneck for livestock production and productivity, and is prompting trade embargos for livestock and livestock products (Mansley, 2011). According to the office of international des epizootics, FMD ranks first among the disease of animals (Mahy, 2005). It is caused by FMD virus (FMDV) which belongs to the genus Aphthovirus within the family Picornaviridae (Belsham, 2005). The disease is characterized by fever, loss of appetite, salivation, vesicular eruptions in mucosa of the mouth, skin of the inter-digital spaces and coronary bands of the feet and teats, and sudden death of young stock (Quinn, 2005; OIE, 2009). Foot and mouth disease virus (FMDV) exists as seven immunologically distinct serotypes; namely, O, A, C, Asia 1, Southern African Territories (SAT)-1, SAT-2 and SAT-3 (OIE, 2004) with distinct immunologic, antigenic and genetic properties. The seven serotypes also differ in their distribution across the globe (Rufael et al ., 2008; Ayelet et al ., 2009). Currently, five FMDV serotypes (O, A, C, SAT-1 and SAT-2) are identified in Ethiopia out of the seven serotypes of the virus (Ayelet et al ., 2009; Negussie et al ., 2011). Within each serotype, there are many bio typical strains and topotypes which can be identified by genetic and immunological tests and infection with one serotype does not confer immune protection against another (OIE, 2012). Type $\mathrm{O}$ and $\mathrm{A}$ are the dominant serotypes responsible for substantial economic losses (Negussie et al ., 2011). Generally, studies undertaken on FMD so far revealed the existence of the disease in different parts of the country, with seroprevalence varying from $8.18 \%-44.2 \%$ in different part of the country (Mohamoud et al ., 2011; Jenbere et al ., 2011). 
The disease spreads rapidly by movement of infected animals or mechanically via fomites such as clothing, shoes, vehicles, and veterinary instruments (Jibat et al ., 2013). The reasons for the rapid spread to fully susceptible population is due to its highly infectious nature of the virus, production of high titer in respiratory secretions and large volumes of droplets and aerosols of virus shed by infected animals, stability of virus in such droplets, rapid replication cycle with very high virus yields and short incubation period of the virus (Rweyemamu et al., 2008). FMD is the major endemic disease in Ethiopia with abundant socioeconomic importance as a result of reduced production, deaths in newborn animals, huge cost of veterinary services, restricted animal and meat movement locally and between countries (Knight-Jones and Rushton, 2013). Moreover, livestock and livestock product exports to the Middle East and African country has been hampered because of the presence of FMD recently (Bayissa et al ., 2011). The Egyptian ban of 2003 on Ethiopia's livestock market alone resulted in market loss of 14.36 million USD and it is a threat to Ethiopia's live animal export and export of animal products (MoARD, 2007 and MoARD, 2009).

In Ethiopia, outbreak of FMD frequently occurs in the pastoral herds of the marginal low land areas of the country (Mesfin, 2011). Absences of livestock movement control coupled with absence of systematic disease surveillance contribute a lot for outbreak of FMD in the pastoral herds of the marginal lowland areas of Ethiopia (Sahle et al ., 2004). There is limited information regarding to FMD virus serological status which may help to generate important baseline information about the disease in the study areas. Hence, the present study was anticipated to determine the seroprevalence and assess potential risk factors associated with occurrence of FMD virus in selected districts of afar region.

\section{Materials and Methods}

\section{Description of the study areas}

The study was conducted from November, 2018 to May, 2019 in three districts namely (Asayita, Dubti and Chifra), which are Located in the administrative zone one of Afar Region, Ethiopia. The Afar Pastoral Region is located in northeast of Ethiopia between $39^{\circ} 34^{\prime}$ to $42^{\circ} 28^{\prime} \mathrm{E}$ longitude and $8^{\circ} 49^{\prime}$ to $14^{\circ} 30^{\prime} \mathrm{N}$ latitude (Figure 1). The region shares common international boundaries with Eritrea in the northeast and Djibouti in the east and it is characterized by an arid and semi-arid climate with low and erratic rainfall. Rainfall is bi-modal throughout the region, with a mean annual rainfall below $500 \mathrm{~mm}$ in the semi-arid western escarpments and decreasing to $150 \mathrm{~mm}$ in the arid zones to the east. The altitude of the Region ranges from $120 \mathrm{~m}$ below sea level in Danakil depression to $1500 \mathrm{~m}$ above sea level. Temperatures vary from $20^{\circ} \mathrm{C}$ in higher elevations to $48^{\circ} \mathrm{C}$ in lower elevations. The human population of Afar region is 1.5 million in which the majority are pastoralists who largely depend on livestock production for their livelihood. There are about 1.9 million Afar breed cattle in Afar Region, of which $90 \%$ of the cattle are managed under pastoral production system and the rest 10\% in agro-pastoral production system (ANRS, 2010). 

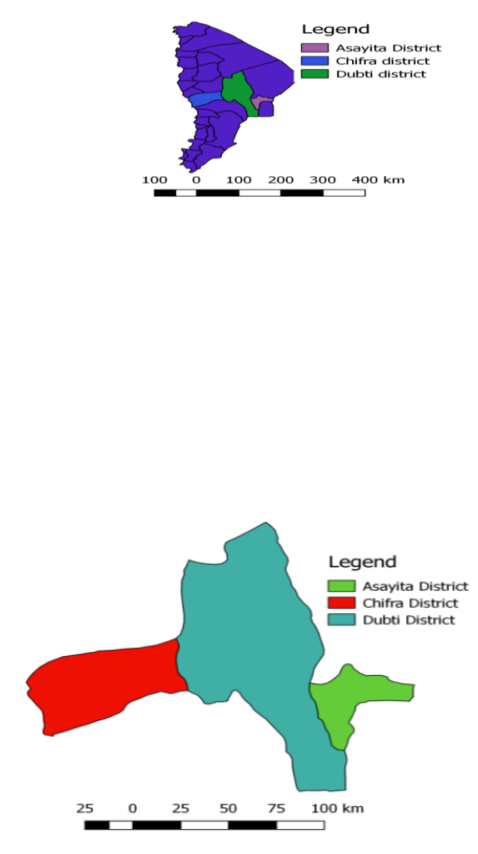

Figure 1: Map of Afar Pastoral Region indicating the study districts

\section{Study populations}

The study populations were afar indigenous breed of non-vaccinated cattle above the age of six months having no clinical symptom of any disease were included. The age groups were Considered as ([?]3.5years) Young, (3.5years $<\mathrm{x}[?] 5.5 y e a r s)$ Adult and ( $>5.5 y e a r s)$ Old (pace and walker, 2003). In addition, herd size was considered small ( $<40$ cattle), medium ( $40-75$ cattle) and large ( $>75$ cattle) (Tolosa et al ., 2015). These study populations were reared by pastoralists and agro-pastoralists in the selected districts of the region and these animals are usually kept mixed with other animal species.

\section{Study Design}

A cross sectional study design was employed to determine the seroprevalence of FMD and associated risk factors in three selected districts of afar pastoral region and a total of 72 herds were included in the study based on the inclusion criteria. A semi-structured questionnaire was administered to herd owners for the assessments of animal and herd level risk factors.

\section{Sampling technique and Sample Size determination}

Multistage sampling technique was employed to select study population by taking 'district' as the first stage, 'pastoral association' as the second stage, and 'herd' as the third stage. Study districts were purposively selected based on higher study population, access to transportation, history of outbreaks and willingness of pastoralists to participate in this research work for seroprevalence determination and assessment of potential risk factors of FMDV. Finally, individual animal from each herd was selected randomly as secondary sampling unit to attain the required sample size. Since there is no previous study conducted on FMD in cattle found 
in the selected areas, the present study has considered 50\% expected prevalence, 95\% confidence level and $5 \%$ absolute precision or marginal error. Based on these assumptions, the total number of animals to be included in the study got determined using Thrusfield (2007) formula.

\section{$\frac{Z^{2} \times P \exp (1-P \exp )}{d^{2}}$}

Where $\mathrm{n}=$ required sample size, $\mathrm{d}=$ desired absolute precision $(0.05), \mathrm{Z}=$ Multiplier from normal distribution at $95 \%$ Confidence interval (1.96), $\mathrm{P}_{\text {exp }}=$ expected prevalence $(50 \%),\left(1-\mathrm{P}_{\text {exp }}\right)=$ Probability of having no disease $50 \%$ (0.5). Accordingly, a total of 384 study populations were sampled from all three districts. Proportionally, a total of 147, 97, and 140 serum samples were collected from Asayita, Dubti and Chifra respectively based on density of cattle population in the study districts.

\section{Sample Collection and Transportation}

A total of all 384 whole blood samples each approximately amounting to 8-10ml was collected from jugular vein of cattle using disposable needles and $10 \mathrm{ml}$ non-heparinized vacutainer tube and 21 Gauge needle. Following whole blood sample collection, vacutainer tubes were labeled and transported to laboratory and kept overnight at room temperature to allow the blood clot at slant position. Correspondingly, each sample was identified along with sex, age, herd size and district. Then, serum samples were transferred from vacutainer tubes to cryogenic vials and stored in $-20^{\circ} \mathrm{C}$ refrigerator at Samara University veterinary medicine microbiology laboratory. Finally, the serum samples were transported in an ice box via air plane to the National Veterinary Institute (NVI), upon arrival; the sera was stored at -20degC until further processing took place and the samples were tested using the FMD non-structural protein ELISA to determine if animals in the herd had been recently infected with FMD virus thereby estimating the seroprevalence in the three selected districts of afar region.

\section{Administration of Questionnaire Survey}

Open and closed ended questionnaires were administered to herd owners to assess potential risk factors of the disease alongside with sample collection. Respondents from each district were randomly selected and interviewed to assess potential risk factors of the disease. Study populations' sex, age, herd size and district were considered as hypothesized risk factors for the occurrence of FMDV. The questionnaires were interpreted into Afaraf language. Herd owner having cattle were the sampling units for questionnaire survey. Accordingly, herd owners included from three districts in this questionnaire survey were 27 from Asayita, 20 from Dubti and 25 from Chifra, a total of 72 herd owners were interviewed. All necessary epidemiological information was collected tabulated, coded and analyzed using suitable statistical analysis on individual animal bases.

\section{Serological Diagnostic Test}

The collected sera were tested by commercially available FMDV-3ABC-Ab ELISA kit (Non-structural proteins $3 \mathrm{ABC}$ of FMD virus infection) (ID Screen(r) FMD NSP Competition, ID-VET, Grabels, France) for the detection of antibody to $3 \mathrm{ABC}$ poly-protein which is a useful indicator of past FMDV infection regardless of the serotype involved. The 3-ABC-ELISA was used according to the manufacturer's instructions. The test principle is the blocking of plate bound NSP antigen by antibodies present in the serum samples. Any antibody specific for $3 \mathrm{ABC}$ binds to the antigen in the wells and forms an antigen/antibody complex on the plate well surface. Antibody to the assay was performed according to manufacturer's instruction and results were analyzed and interpreted using:

\section{Hosted file}


image5.emf available at https://authorea.com/users/321150/articles/450461-seroprevalence-ofbovine-foot-and-mouth-disease-fmd-and-its-associated-risk-factors-in-selected-districtsof-afar-region-ethiopia

According to the ELISA test kit manual, the samples were categorized based on their optical density (OD values as negative if $\mathrm{OD}$ value $<20 \%$, ambiguous if OD value is between 20-30\% positive if OD value is $>$ $30 \%)$.

\section{Data Management and Analysis}

Data generated from laboratory analysis and questionnaire survey were recorded and coded using Microsoft Excel spreadsheet (Microsoft Corporation) and analyzed using STATA version 14.0 for Windows (Stata Corp. College Station, TX, USA). Descriptive statistics (frequency and percentage) were employed to calculate the proportion of risk factors for FMD. Individual level animal prevalence was calculated by dividing the number of animals with positive ELISA tests by the total number of tested animals, and the herd prevalence was determined by dividing positive herds by the total number of herds. Herds were considered positive if one or more animals in the herd had a positive ELISA test. Risk factors for seroprevalence of FMD virus were investigated using logistic regression analysis. In all the analyses, confidence levels at $95 \%$ were calculated, and a $\mathrm{P}<0.05$ was used for statistical significance level.

\section{Results}

In the current study, from a total of 384 sera collected from the study population and tested by $3 \mathrm{ABC}$ Ab ELISA, 19.8\% ( $\mathrm{n}=76)$ were found to be positive to FMDV. All variables were categorical type and descriptive statistics was employed to calculate the proportion of risk factors with respective categories and frequency with proportion of each category has been computed and summarized (Table 1). Majority of study population, $81.25 \%(\mathrm{n}=312)$ were female while about $18.75 \%(\mathrm{n}=72)$ of them were males.

Table 1 : Summary of descriptive statistics of variables

Variable Levels Frequency (\%)

Sex Female 312(81.25)

Male 72(18.75)

Age Young $(<3.5$ years) $127(33.07)$

Adult (3.5-5.5 years) $122(31.77)$

Old ( $>5.5$ years) $135(35.16)$

Herd size Small (< 40 animals) 124(32.29)

Medium (40-75 animals) 142(36.99)

Large (> 75 animals) 118(30.73)

Contact with No 119(30.99)

Wild life Occasionally 157(40.89) Regularly 108(28.13)

Contact with PA No 52(13.54)) Occasionally 126(32.81)

Regularly 206(53.64)

District Asayita 147(38.28)

Dubti $97(25.26)$

Chifra 140(36.46) 
Total 384(100\%)

$\mathrm{PA}=$ Peasant association

\section{Seroprevalence of Foot and Mouth Disease Virus (FMDV)}

Out of 384 sera tested using FMD 3ABC-ELISA test, the overall seroprevalence of FMDV at individual animal level was found to be $19.8 \%(\mathrm{n}=76 / 384)$ with $95 \%$ CI $(15.8,23.79)$ and at the herd level was found to be $56.94 \%$ ( $\mathrm{n}=41 / 72)$ from study population as indicated in (figure 2 ).

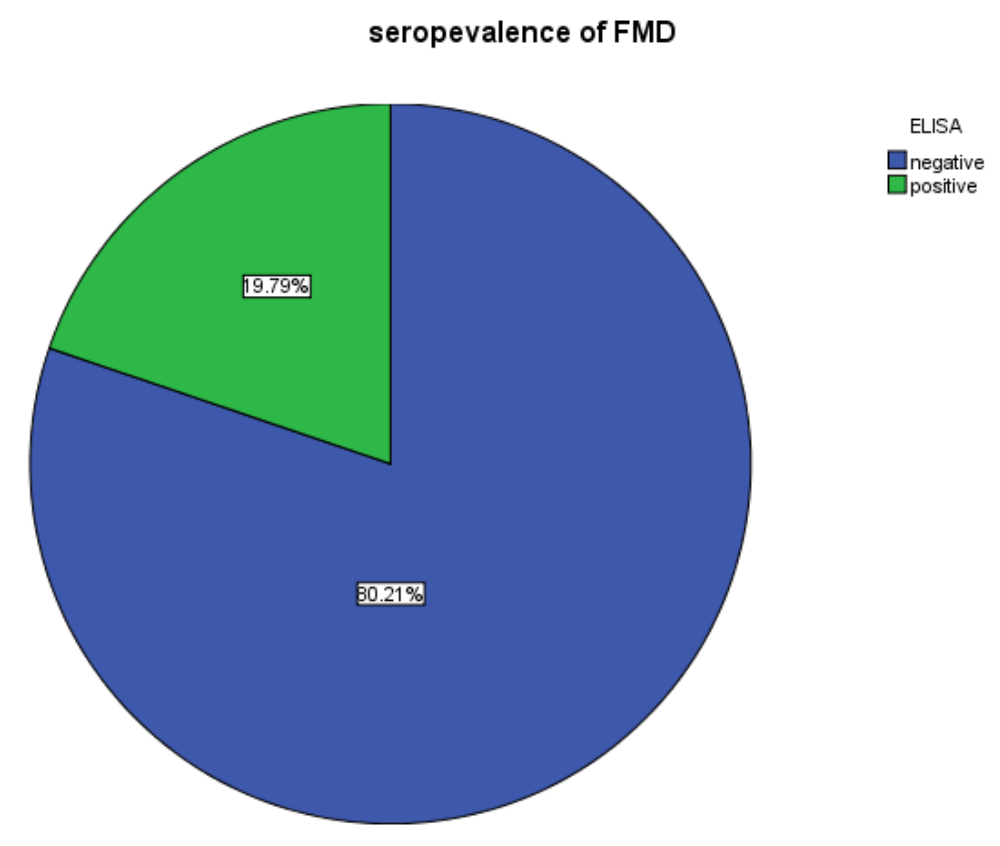

Figure 2: Seroprevalence of FMD from study districts of Afar region using3 ABC ELISA test

The higher herd level seroprevalence was recorded in dubti district (85\%) as shown in (figure 3) which was significant different $(\mathrm{P}<0.05)$ from other districts as depicted (Table 2$)$.

Table 2: Herds Seroprevalence of FMD in cattle in three districts of Afar region

District $\mathrm{N} o$ of $\mathrm{N} o$ of $\mathrm{N} o$ of Herd level

Herd positive positive seroprevalence (\%)

Animals Herd

Asayita 272213 48.13\%

Dubti $20341785 \%$

Chifra $25201144 \%$

Total $72764156.94 \%$ 


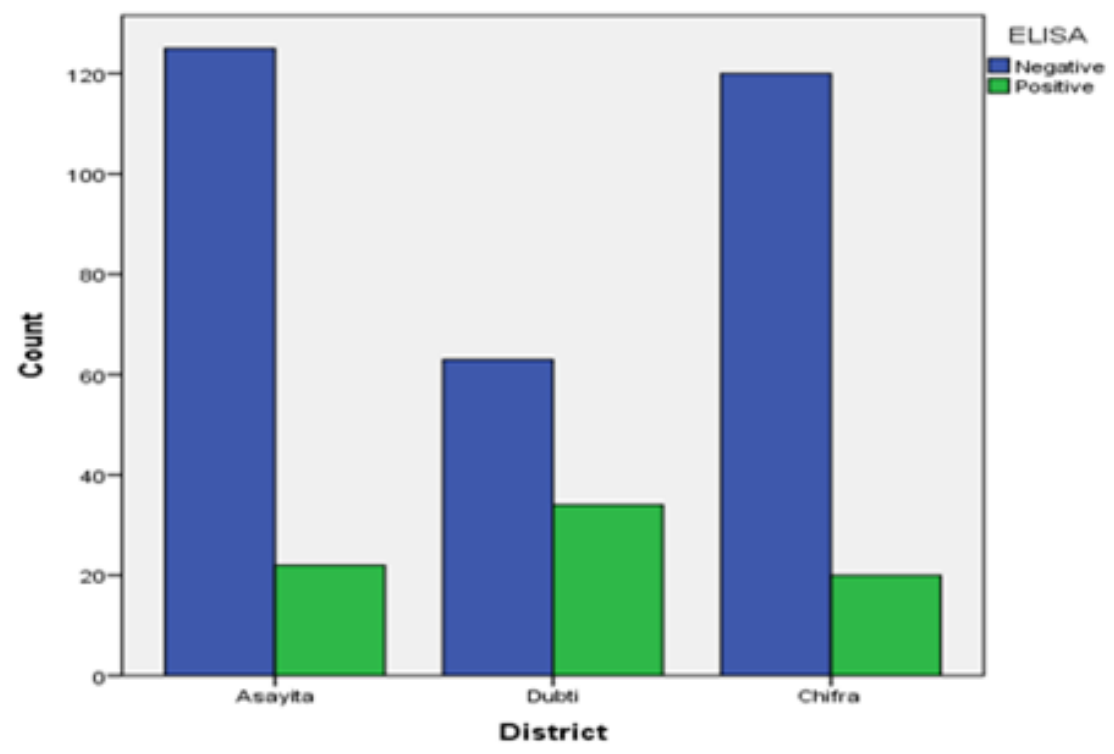

Figure3: Seroprevalence of FMD at individual animal level in study districts

\section{Risk Factor Analysis for FMD seroprevalence}

Study populations' sex, age, herd size and district were considered as hypothesized risk factors for the occurrence of FMDV. Comparison of FMD seroprevalence between sex groups revealed a highest prevalence of $14.84 \%(57 / 384)$ in female cattle than male ones $3.90 \%(15 / 384)$ (Table 3). However, this seroprevalence variation was not statistically significant $(\mathrm{P}>0.05)$. Seroprevalence of antibodies against FMDV was compared between different age groups of the study populations. An increasing seroprevalence trend was observed with increasing age and the difference was statistically significant. FMD seroprevalence and herd size seems to have positive relationship in that an increasing seroprevalence of antibodies against FMDV was observed as herd size increases (Table 3 ) and this difference was statistically significant $(\mathrm{P}<0.05)$. Moreover, comparison of FMD seroprevalence between study districts revealed statistically significant variation.

\section{Logistic regression analysis of Risk factors}

The uni-variable and multivariable logistic regression analysis included effects of age, herd size, study district and contact with animals from different pastoral association. In the current study finding, logistic regression analysis revealed that age, herd size and study districts have a direct relationship with seropositivity and FMDV. The age groups of cattle was found statistically significant, which means adult cattle were 2.97 times more $(\mathrm{AOR}=2.97,95 \% \mathrm{CI}: 1.33,6.63)$ likely to have a chance of contracting FMD than young cattle. In regard to herd size, animals from medium herd size were 2.49 times more $(\mathrm{AOR}=2.49,95 \%$ CI: 1.05, 5.92) likely to develop the disease as compared to small herd size animals. Similarly, cattle from large herd size were 6.05 time more $(\mathrm{AOR}=6.05,95 \% \mathrm{CI}: 2.54,14.43)$ likely to develop the disease as compared to animals from small herd size. District was also found to be statistically associated with FMD incidence. Hence, animals found in Dubti district were 2.49 times more ( $\mathrm{AOR}=2.49,95 \%$ CI: 1.19, 5.17) likely to develop the disease as compared animals found in Asayita district as depicted (table 3). Animals' contact with ungulate wild life was also used as risk factors and found statistically significant and cattle that contact regularly with ungulate wild life 8.97 times more $(\mathrm{AOR}=8.97,95 \% \mathrm{CI}: 3.24,24.8)$ likely to develop the disease as compared to cattle having no contact with wild life by keeping other factors constant.

Table3: Summary of univariable and multivariable logistic regression analysis of potential risk factors associated with FMD in Selected districts of afar region. 
Variables

Sex Female Male

Age Young Adult Old

Herd size Small Medium Large

District Asayita Dubti Chifra

Contact with wild life No Occasionally Regularly

Contact with animals from different peasant associations No Occasionally Regularly
ELISA test result $\operatorname{COR}(95 \%$

$-+$

251576115

11413893310530

1159115277840

12522633412020

1127134236246

4931081815155
1 1.08(0.57-2.

$13.25(1.62-6$

$13(1.35-6.66$

$13.06(1.65-5$

$12.75(1.14-6$.

$12.72(0.76-9$

Note: $\mathrm{COR}=$ Crude odds ratio; $\mathrm{AOR}=$ Adjusted odds ratio; $\mathrm{CI}=$ confident interval; $*=$ significant; $\mathrm{ns}=$ non-significant; $1=$ Reference factor; - = negative sample; $+=$ positive sample.

\section{Discussion}

The present study revealed that FMD is a significant disease in the study districts with a seroprevalence of $19.8 \%(\mathrm{n}=76 / 384)$. The current study finding indicated that the overall seroprevalence of FMDV at individual animal level was $19.8 \%$ in the study areas, which is in close agreement with the previous seroprevalence records of $21 \%$ in the Borana pastoral area (Rufael et al ., 2008), 21\% in Borana zone and Guji zone (OIE \& FAO, 2013), 21\% in kellema Wollega Zone (Fanta et at ., 2014), 21 \% in Borna pastoral area (Tesfaye, 2006). In contrast to the current study finding, lower seroprevalence of FMD was previously reported as mentioned below; $13 \%$ in selected districts of western Ethiopia (Tolosa et al ., 2015), 10.88\% in selected district of eastern showa zone, Oromia regional state (Dinaol et al ., 2016), 12.05\% in the Bench Maji zone, Southern Ethiopia (Gelaye et al ., 2009), 8.8\% in South Omo Zone (Molla et al ., 2010), 9.5\% from indigenous cattle in southern Ethiopia (Megersa et al ., 2009), 5.53\% on quarantined bulls for export at Nazareth and Dire Dawa stations (Bedru, 2006) and 4.8\% in selected districts of western, Oromia (Milkessa et al ., 2016). These relative lower seroprevalence of FMD in comparison to the current study might attributed to diagnostic tests employed, the sampling method, study population and sites, the geographic structure and timing of infection, the pastoral production system, which is characterized by a high level of herd mobility in search of pasture and water, intermingling of animals at watering points, large herd sizes and frequent contact with the livestock of neighboring countries through cross-border contact as well as contact of livestock with FMD virus reservoirs' of wildlife such as buffalo, wild pigs, kudu and warthog and other factors (Gelayeet al ., 2009; Megersa et al ., 2009). On the other hand, relatively higher seroprevalence was previously reported in comparison to our study from Borna pastoral and agro-pastoral area with 23\% (Berecha et al ., 2011), in Borena and Guji Zones with 24.6\% (Mekonnen et al., 2011), in west Shewa zone, North Shewa zone and Addis Ababa with 30.8\% (Beksisa, 2017), 32.7\% in Guji zone of Oromia region and $30 \%$ in Yeka district of the city of Addis Ababa as well as eastern zone of Tigray with 41.5\% (Ayelet et al., 2012) and 28.3\% seropositivity in Akaki-kality sub-city (Nigussie et al ., 2011). A study finding from neighboring Sudan also revealed that following an active occurrence of the disease, the seroprevalence of FMD was reported with $79 \%$ in cattle (OIE, 2012). Moreover, according to Hafez et al . (2014), FMD seropositivity was reported in Saudi Arabia with 53\% seroprevalence and Namatovu et al. (2015) as well reported $77 \%$ in infected cattle in Uganda. This seropositivity variation could be resulted from differences in individual animal breed, immune status, interaction of cattle with other animals and production system as well as differences in geographical area or the way sampling was conducted based on the existence of recent outbreak cases, sample size, methodology, regular contact with ungulate wildlife (Gelayeet al ., 2009).

The overall herd level seroprevalence in this study was $56.9 \%(\mathrm{~N}=41 / 72)$. This finding was in line with the findings of Tesfaye (2006), who reported the seroprevalence rate of $59 \%$ in Borna pastoral area, Berecha et al ., (2011), who reported 58.6\% in Borna pastoral and agro pastoral area. The highest herd level seroprevalence (85\%) recorded in Dubti as compared to Asayita (48.13\%) and Chifra (44\%); this might be due to the fact that, Dubti is centers for cattle markets and have high population of small ruminant. This suggests that small ruminants have an important role in the epidemiology of FMD as they can serve as potential carriers and transmitters of the disease (Jenbereet al ., 2011) and (Mohamud et al ., 2011). 
Among the risk factors considered in the current study age, herd size, district and contact with ungulate wild life were found to be statistically significant $(\mathrm{P}<0.05)$ in multivariate logistic regression. In this study, the prevalence of FMD in adult age group was higher than in young group and this age specific seropositivitity of FMD was statistically non-significant. Thus, Adult cattle were 2.97 times more likely to have a chance of contracting FMD than young cattle. This statistically significant higher seroprevalence of FMDV in old and adult animals than young cattle in this current study finding was in accordance with earlier studies of Tolosa et al . (2015) who reported that adult cattle were 2.7 times more likely to have the chance of develop disease than young cattle in western Ethiopia, Berechaet al . (2011) in Borna pastoral and agropastoral area, Mollaet al . (2010) in south Omo zone and Megersa et al. ( 2009) in Gamogofa and Sidama zones, Chepkwony et al . (2012) in Awbere and Babille districts of Jijiga zone. Age association with FMD seroprevalence was also in close agreement with the previous study of (Olabode et al ., 2013). The possible justification for age association with FMD seroprevalence could be due to adult cattle have acquired the infection through frequent exposure over time to multiple serotypes of the virus and could get access to mix with other herds at communal pasture land and market places. Furthermore, it might be due to persistence of antibodies against FMDV for extended periods of time (Sangare, 2005). Relatively low seroprevalence in animal groups below 2 years old might be indicative of the existence of passive maternal immunity and low frequency of exposure (Jenbere et al ., 2011; Mohamoud et al ., 2011). In our study areas, young animals were often managed separately at around homestead so that young's have low frequency of exposure to the virus and they could also prevailing passive maternal immunity can give them protection against the disease. On the contrary, our study result contradicted with Esayas et al . (2009) and Gelaye et al . (2009), who documented no significant association between seropositivity of FMD and age of cattle in Bench Maji zone of southern Ethiopia.

In the current study, seroprevalence of FMD was also significantly influenced by herd size, which means seroprevalence of antibodies against FMDV increased with increasing herd size. In our study result, those animals from medium herd size and large herd size were 2.49 and 6.05 times more likely to develop the disease as compared to those animals from small herd size respectively by keeping the other factors constant. Our research finding was in agreement with Tolosa et al . (2015), Gelaye et al. (2009), Bayissa et al . (2011), Berecha et al . (2011), who reported that they have positive relationship between FMD seroprevalence and herd size. This direct association might be an indication of contagious nature of the disease and mode of transmission, which is attributed to crowding of animals that can facilitate frequency of direct contact and hence enhances chances of transmission.

In our study finding, statistically significant association was found between study districts and FMD seroprevalence of $35.05 \%(n=34 / 97), 14.29 \%(n=20 / 140)$ and $14.97 \%(n=22 / 147)$ in Dubti, Chifra and Asayita district respectively. Thus, cattle found in Dubti district were 2.49 times more likely to develop the disease as compared with those cattle found in Asayita district. Our study finding is in close agreement with previous reports of Milkessa et al . (2016), who reports the significant variation of Horro (8.2\%) and Gobu-sayo $(0.8 \%)$ districts of western Oromia regional state and Molla et al . (2010). This might be due to differences in the movement and distribution of livestock, the level of contact between herds and ungulate wildlife and the grazing type in each administrative structure. (Ekboir, 1999) also suggested that movements of infected animals are by far the most important dissemination and transmission means for FMDV. Again Paulet al . (1996) in northern Thiland and Bronsvoort et al . (2004) in Cameroon observed the influence of cattle movement and keeping animals at homestead in the incidence of FMD.

Cattle that contact regularly with ungulate wild life were 8.97 times more likely to develop the disease as compared to cattle having no contact with wild life by keeping other factors constant. This study finding was in agreement with previous studies of Tolosa et al . (2015) in western Ethiopia and Molla et al . (2010) in South Omo zone who reported that cattle that regularly contact with ungulate wildlife were 3.3 times more likely to develop the disease than cattle having no contact with wild life. According to Bronvoort et al . (2008) contact between ungulate wildlife and livestock at watering points and grazing areas is the main risk factor for FMDV circulation and it is a challenge for disease control in East Africa (Lazarus, 2012). Although Statistical analysis using the chi-square test and uni-variable logistic regression showed that contact 
with animals from different peasant association/herds appeared to have a significant effect on seropositivity, multivariable logistic regression showed that contact animals to other herds/peasant association had no statistically significant relationship with the seropositivity of the animals $(\mathrm{p}>0.05)$. It was a confounding factor in the relationship between seropositivity and contact with herds/PAs. However, this result contradict with Tolosa et al . (2015), who reported the herds were 3.4 times more likely to be seropositive for FMD than herds that did not have a history of contact with other herds. The difference from the present study might be because of unequal involvement of differently contact animal groups in our sampling where majority of our study animals were animals that regularly contact with other herds/PAs due to accessibility.

\section{Conclusions}

The current study finding indicated an overall bovine FMD seroprevalence of $19.8 \%$ at individual animal and $56.8 \%$ at herd level in the study districts. Hence, our result revealed that FMD was prevalent and is an important cattle disease in the study districts and causing significant economic reduction of daily milk yield, abortion, loss of traction power, and death of calves during outbreaks. Multivariable logistic regression analysis revealed that seroprevalence of FMD was statistically associated with age, herd size, district and contact with wildlife as potential risk factors in the district areas of afar region necessitating further investigation and characterization of circulating virus serotypes to apply effective control and prevention measures.

\section{Acknowledgments}

The authors would like to thank Research and Community service office of Samara University for funding this research project and National Veterinary Institute-Ethiopia for the provision of laboratory facilities and space to execute this research work. We would like to extend our thanks to college of veterinary medicine staffs and cooperation of herd owners in the study areas during data and sample collection.

\section{Funding}

The cost of this research work was covered by Samara University, Research and community service office.

\section{Availability of data and materials}

The data sets used and/or analyzed during the current study available from the corresponding author on reasonable request.

\section{Ethics approval and consent to participate}

Ethical approval and consent for this study was obtained from Samara University College of Veterinary Medicine of Animal Research Ethics and Review committee (Reference AREC019/2019). Verbal consent was also obtained from the farm managers to take samples from their cattle and for further research use of the samples.

\section{Consent for publication}

Not applicable

\section{Conflict of interest}

The authors, therefore, declare that they have no competing interests in the publication of this paper

\section{References}

1. Afar Pastoral, Agricultural and Development Bureau (2006): Baseline survey made on the Potential, Constraints, and Opportunity on the Production System of 29 districts of Afar National Regional State.

2. Asseged, B. (2005): Review of Foot and Mouth disease: An in depth discourse of Global, Sub Saharan and Ethiopian status; Addis Ababa University Faculty of Veterinary Medicine, Research and Graduate studies. Debre Zeit, Ethiopia. Pp. 3-49. 
3. Ayelet, G., Mahapatra, M., Gelaye., E, Egziabher, GB., Rufeal, T., Sahle, M., Ferris, NP., Wadsworth, J., Hutchings, HG., Knowles, JN. (2009): Genetic characterization of foot and mouth disease viruses, Ethiopia, 1981-2007. J. Emer. Infec. Dis. ,15 (9):1-40.

4. Ayelet, G., Gelaye, E., Negussie, H. and Asmare, K. (2012): Study on the epidemiology of foot and mouth disease in Ethiopia. Rev. Sci. off. Int. Epiz ., 31 (3):789-798.

5. Ayelet, G., Mahapatra, M., Gelaye, E., Egziabher, G., Rufeal, T. and Sahle, M. (2009): Genetic characterization of foot-and-mouth disease viruses Ethiopia 1981-2007.J. Emerg. Infect. Dis.,15 (9):14091417.

6. Bayissa, B., Ayelet, G., Kyule, M., Jibril, Y. and Gelaye, E. (2011): Study on seroprevalence, risk factors, and economic impact of foot and mouth disease in Borana pastoral and agro pastoral system, southern Ethiopia. Trop. Anim. Hlth Prod., 43 (4), Pp. 759-766.

7. Bedru, H. (2006): Sero-prevalence study of foot and mouth diseases in export bulls of Borena and Jimma origin, Ethiopia. DVM thesis, Faculty of Veterinary Medicine, Addis Ababa University, Bishoftu, Pp: 18.

8. Belsham, GJ. (2005): Translation and replication of FMDV RNA.Curr. Top. Microbiol. Immunol. $288,43-70$.

9. Berecha, B., Gelagay, A. Moses, K., Yasmin, J., Esayas, G. (2011): Study on seroprevalence, risk factors, and economic impact of foot-and-mouth disease in Borena pastoral and agro-pastoral system, southern Ethiopia; Trop. Anim. Health. Prod . 43 :Pp. 759-766.

10. Bronsvoort, B., Nfon, C., Hamman, S., Tanya, V., Kitching, R., Morgan, K. (2004): Risk factors for herds man-reported foot and Mouth Disease. Characterization of foot and mouth disease viruses, Ethiopia, 1981-2007, CDC. Emerg. Infect. Dis ., 15 : Pp. 1409-1417.

11. Bronvoort, D., Parida, S., Hande, I., Macfarland, S., Fleming, L. and Hamblin, P. (2008): Serological survey for foot and mouth disease in wildlife in Eastern Africa and estimation of test parameters of a non-structural protein ELISA for buffalo. Clin. Vaccine Immunol ., 15 (6), Pp. 1003-1011.

12. Chepkwony, C., Gitao, G. and Muchemi, M. (2012): Seroprevalence of foot and mouth disease in the Somali eco-system in Kenya. Int. J. Anim. Veter.Adv ., 4 (3):198-203.

13. CSA. Central Statistical Agency (2016): Report on livestock and livestock characteristics. Vol II, Statistical Bulletin.583.p.

14. CSA. Central Statistical Authority (2009): Federal Democratic Republic of Ethiopia, Central Statically investigation, statically Abstract.

15. Dinaol, B., Yimer, M., Birhanu, G. and Shimelis, M. (2016): Sero-prevalence of Bovine Foot and Mouth Disease in Selected Districts of Eastern Showa Zone, Oromia Regional State, Ethiopia Global Journal of Science Frontier Research: D. Agri. and Veter. 16:Pp. 34-43.

16. Ekboir, J. (1999): Potential impact of foot and mouth disease in California; the contribution of animal health surveillance and monitoring, California. Agric. Res. Manage., Pp. 7-13.

17. Esayas, G., Gelagay, A., Tsegalem, A., Kassahun, A. (2009): Seroprevalence of foot and mouth disease in Bench Maji zone, southwestern Ethiopia. J. Vet. Med. Anim. Health , 1: Pp 5-10.

18. Fanta, D., Desalgn, T., Bedaso, M. and Tesfaye, R. (2014): Epidemiological study on Foot and Mouth Disease in cattle; seroprevalnce and risk factors assessment in kellmewollega zone, west Ethiopia. African journal of Agricultural research. College of veterinary medicine and agriculture, Addis Ababa University Bishoftu, Ethiopia.

19. Ganeshkumar, B. (2012): Economic Impact of Foot-and-Mouth Disease in India, Scientific Developments and Technical Challenges in the Progressive Control of Foot-and-Mouth Disease in South Asia, New Delhi, India. Glob. Res. Alli.; 13:5.

20. Gebreegziabhare, B. (2010): An over view of the role of Ethiopian livestock in livelihood and Food safety. Ministry of Agriculture and Rural development of Ethiopia; Presente on dialogue on livestock, food security and sustainability, a side event on the session of 22 COAGO, FAO, Rome; p. 581-593.

21. Gelaye E., Ayelet G., Abera, T. and Asmare, K. (2009): Seroprevalence of foot and mouth disease in Bench Maji zone, Southwestern Ethiopia.J. Vet. Med. Animal Health , 1 (1), 5-10. Available at: www.academicjournals.org/JVMAH (accessed on 20July 2019). 
22. Hafez, S.M., Farag, M.A., Mazloum, K.S. and Albokmy, A.M.(2014): Serological survey of FMD virus in Saudi Arabia. Rev. Sci. Tech. Off. Int . Epiz ., 13 (3): 711-719.

23. Jenbere, S., Etana, M., and Negussie, H. (2011): Study on the risk factors of foot and mouth disease in selected districts of afar pastoral area. Northeast Ethiopia J. Anim. Vet. Adv. ,10 (11):1368-72.

24. Jibat, T., Admassu, B., Rufael, T., Baumann, M., and Potzsch, C. (2013): Impacts of foot-and-mouth disease on livelihoods in the Borena Plateau of Ethiopia. Pastoralism. Rev. Sci. Tech .21, Pp. 499-504.

25. Knight-Jones, T.J.D. and Rushton, J. (2013: The economic impacts of foot and mouth disease what are they, how big are they and where do they occur? Prev. Vet. Med. 112, 161-73. doi:10.1016/j.prevetmed.2013.07.013.

26. Lazarus, D., Schielen, W., Wungak., Y. Kwange, D. and Fasina, F. (2012): Sero-epidemiology of foot and mouth disease in some border states of Nigeria. Afr. J. Microbiol . Res., 6 (8), Pp.1756-1761.

27. Livestock Master Plan (2015): Agricultural sample survey on livestock and livestock characteristics. Federal Democratic Republic of Ethiopia. Central statistical Agency.

28. Mahy, W. (2005): Foot and Mouth Disease Virus, p3. Springer-Verlag, Heidelberg, Germany.

29. Mansley., LM, Donaldson., AI, Thrusfield, MV. And Honhold, N. (2011): Destructive tension: mathematics versus experience-the progress and control of the foot and mouth disease epidemic. Rev. scientifique et tech. 30:483-98

30. Megersa., B, Beyene., B, Abunna., F, Regassa., A, Amenu, K. and Rufael, T. (2009): Risk factors for foot and mouth disease seroprevalence in indigenous cattle in Southern Ethiopia: the effect of production system. Trop. Anim. Hlth Prod. , 41 (6), 891-898. doi: 10.1007/s11250-008-9276-5.

31. Mekonen., H, Beyene., D, Rufael., T, Feyisa., F. and Abunna, F. (2011): Study on the prevalence of foot and mouth disease in Borana and Guji zones, southern Ethiopia. Vet. World , 4 (7),Pp. 293-296.

32. Mesfin, S., 2011. An Epidemiological study on the Genetic relationships of Foot and Mouth Disease virus in East Africa, PhD Thesis, University of Pretoria, South Africa, Pretoria.

33. Milkessa, G., Tesfaye, M., Tesfaye, M. and Habtamu, A. (2016): Sero-prevalence Study on Foot and Mouth Disease in Selected Districts of Western Oromia Journal of Pharmacy and Alternative Medicine.An Inte. Peer-reviewed Journal Bako Agri. Resea. Cen., Bako, Ethiopia: 13: Pp. 34-40.

34. MoARD. (2007): Livestock Development Master Plan Study. Phase I Report, Data Collection and Analysis. Volume B Meat Production. Ministry of agriculture and rural development, Government of Ethiopia, Addis Ababa, Ethiopia.

35. MoARD. (2009): Ministry of Agriculture and Rural Development Animal and Plant Health Regulatory Directorate. Foot and mouth disease outbreaks annual report recording data summary from the years 1999-2008, Addis Ababa, Ethiopia.

36. Mohamoud., A, Tessema, E. and Degefu. H. (2011): Seroprevalence of bovine foot and mouth disease (FMD) in Awbere and Babille districts of Jijiga zone, Somalia regional state, eastern Ethiopia. Afri. J. Microbio . Res. 5 (21):3559-63.

37. Molla, B., Ayelet, G., Asfaw, Y., Jibril, Y., Ganga, G. and Gelaye, E. (2010): Epidemiological Study on Foot-and-Mouth Disease in Cattle: Seroprevalence and Risk Factor Assessment in South Omo Zone, South-western Ethiopia. Trans-boundary and Emerg. Dis.,57 (5): Pp. 340- 347.

38. Namatou,A., Sebenzia, N., Tjornehoj, K., Muwanika., Siegismund, H., Namatovu, A. and Ayebazibwe, C. (2015): Characterization of FMD virus from Ugandan cattle outbreaks during 2012-2013: Evidence for circulation of multiple serotypes. J. Resea. ,10 (2): $44-116$.

39. Negussie, H., Moses, Kyule, N., Yami, M., Ayelet, G. and Jenberie, T. (2011): Outbreak investigations and genetic characterization of foot and mouth disease virus in Ethiopia. Trop. Anim. Health. Prod ., 43:235-243.

40. Negussie, H., Moses, Kyule, N., Yami, M., Ayelet, G. and Jenberie, T. (2011): Outbreak investigations and genetic characterization of foot and mouth disease virus in Ethiopia. Trop. Anim. Health Prod.,43:235 -243.

41. OIE (World Organization for Animal Health), (2012): Manual of Standards for Diagnostic Tests and Vaccine. Volume $\mathbf{1}$, part 2. 
42. OIE. (2004): Foot and mouth disease. In: Manual of Standards for Diagnostic Tests and Vaccines. 5thed, Office international des Epizooties (OIE), Paris, France. Pp: .111-128.

43. OIE (2010): Manual of Diagnostic Tests and Vaccines for Terrestrial Animals. Lumpy skin disease; 2 (4):768-778.

44. OIE.(2012): Foot and Mouth disease, Manual of Diagnostic Tests and Vaccines for Terrestrial Animals, Version adopted by the World Assembly of Delegates of the OIE in May 2012, OIE Terrestrial.Pp. $1-29$.

45. Pace, J. \& Wakeman, D. (2003): Determining the age of cattle by their teeth. Animal Science Department, Institute of Food and Agricultural Sciences, University of Florida.Available at: wwwq23.extension.umn.edu/youth/mn4-H/projects/ docs/Beef-Mouthing-InfoSheet.pdf (accessed on 21 June 2019).

46. Paul, C., Cleanda, F., Chris, B., Pornchai, C., Laurence, J. (1996): Village level Risk factors for foot and mouth disease in Northern Thiland. Prev. Vet. Med., 26 : Pp. 253- 261.

47. Quinn., PJ, Markey., BK, Carter., ME, Donnelly, WJ. And Leonard, FC. (2005): Veterinary microbiology and microbial disease: Blackwell Science Ltd, A Blackwell publishing company; p. 402-7.

48. Rufael T, Catley A, Bogale A, Sahle M, Shiferaw Y. Foot and mouth disease in the Borana pastoral system, southern Ethiopia and implications for livelihoods and international trade. Trop Anim Health Prod. 2008; 40:29-38.

49. Rweyemamu, M., Roeder, P., Mackay, D., Sumption, K., Brown-lie, J., Leforban, Y., Valarcher, J.F., Knowles, N., and Saraiva, V. (2008): Epidemiological patterns of foot-and-mouth disease worldwide. Trans bound. Emerg. Dis. Pp. 55- 57.

50. Sahle, M. (2004): An epidemiological study on the genetic relationships of foot and mouth disease viruses in east Africa. University of Pretoria, South Africa, Pretoria, PhD Thesis. Pp. 84-107.

51. Sangare O. Molecular epidemiology of foot and mouth disease virus in West Africa. Pretoria: PhD Thesis. University of Pretoria; 2005.

52. Tesfaye, R. (2006): Participatory Appraisal and Seroprevalence study of FMD in Borana Pastoral system, southern Ethiopia, MSc Thesis, Faculty of Veterinary Medicine, Addis Ababa University, Bishoftu, Ethiopia.

53. Thrusfield, M. (2007): Veterinary epidemiology, 3rd Ed. Blackwell Science, Oxford, Pp. 46-65 and $228-242$.

54. Tolosa, T., Beyene, B., Rufael, T., Hailu, B. and Teklue, T. (2015): Foot and mouth disease in selected districts of western Ethiopia: seroprevalence and associated risk factors, Department of Microbiology and Veterinary Public Health, College of Agriculture and Veterinary Medicine, Jimma University, P.O. Box 307, Jimma, Ethiopia, Rev. Sci. Tech. Off. Int. Epiz., 34: Pp. 939-952.

55. World Organisation for Animal Health/Food and Agriculture Organization Foot and Mouth Disease Reference Laboratory Network (2013). - Annual Report 2013. Available at: http://www.wrlfmd.org/ref_labs/ref_lab_reports/OIEFAO\% 20FMD\%20Ref\%20Lab\%20Network\%20Report\%202013.pdf (accessed on 19 September 2015).

\section{Hosted file}

Lists of figures in FMD.docx available at https://authorea.com/users/321150/articles/450461seroprevalence-of-bovine-foot-and-mouth-disease-fmd-and-its-associated-risk-factors-inselected-districts-of-afar-region-ethiopia 